\title{
( $\mu$-Hydroxo)-platinum complex-catalyzed enantioselective aldol reaction of aldehydes with 1-methoxy-2-methyl-1-(trimethylsilyloxy)propene in DMF
}

\author{
Syun-ichi Kiyooka,* Satoshi Matsumoto, Masafumi Kojima, Kazuyuki Sakonaka, and Hirofumi \\ Maeda
}

Department of Materials Science, Faculty of Science, Kochi University, Akebono-cho, Kochi 780-8520, Japan

Keywords: Enantioselective aldol reaction; ( $\mu$-Hydroxo)-platinum complex.

*Corresponding author. Tel.: +81 88 884 8295; fax: +81 88844 8359; e-mail address; kiyooka@cc.kochi-u.ac.jp

\begin{abstract}
R) \text {-BINAP }) \operatorname{Pt}(\mu-\mathrm{OH})]_{2} \cdot 2 \mathrm{OTf}$ catalyzed the enantioselective aldol reaction of aldehydes with 1-methoxy-2-methyl-(1-trimethylsilyloxy)propene at room temperature in dry DMF in high yields with enantioselectivity up to $92 \%$. This is a versatile example of the catalytic enantioselective aldol reaction using a silyl ketene acetal promoted by ( $\mu$-hydroxo)-platinum complexes under mild conditions.
\end{abstract}

Although late transition metal complex-catalyzed enantioselective aldol reactions are expected for industrial processes, the effective catalytic systems have not been developed yet. ${ }^{1}$ The preceding results were quite limited to group 10 metal-catalyzed reactions (palladium ${ }^{2}$ and platinum ${ }^{3}$ ). We have recently reported a practically simplified reaction procedure available for the dicationic (BINAP)- and (sparteine)-palladium-catalyzed aldol reactions with 1-phenyl-(1-trimetylsilyloxy)ethene, in situ providing an active catalyst from $((R)$-BINAP)- or ((-)-sparteine)- $\mathrm{PdCl}_{2}$ and $\mathrm{AgSbF}_{6}$ in the presence of $3 \AA$ molecular sieves in dry DMF. ${ }^{4}$ However, the palladium-catalyzed aldol reactions do not work well with silyl ketene acetals, which are advantageous for the sequential aldol strategy in constructing 1,3-diol frameworks in natural products because it allows preparation of the next aldehyde by the direct reduction of the ester moiety in the aldol products. $^{5}$ On the other hand, a silyl ketene acetal, 1-methoxy-2-methyl-(1-trimethylsilyloxy)propene $\mathbf{1}$, underwent the platinum-catalyzed aldol 
reaction as reported merely by Fujimura, ${ }^{3}$ where an active platinum cationic species was prepared in situ from a Pregosin complex, ${ }^{6}$ 3,5-di-tert-butylsalicylaldehyde-chelating (BINAP)platinum(II) complexes, according to the Strukul method ${ }^{7}$ by treatment with HOTf and lutidine in $\mathrm{CH}_{2} \mathrm{Cl}_{2}$. The in situ formed catalyst (5 mol\% loading) led the aldol reaction of benzaldehyde with $\mathbf{1}$ in $\mathrm{CH}_{2} \mathrm{Cl}_{2}$ at $-25^{\circ} \mathrm{C}$ (21 h) to give the corresponding aldol in a quantitative yield with $59 \%$ ee, although high enantioselectivity was achieved in the reaction with linear aliphatic aldehydes. The valid structure of the active platinum catalyst has not been elucidated yet. In addition, alternative cationic catalysts can also be formed in situ from (BINAP) $\mathrm{PtCl}_{2}$ and $\mathrm{AgX}$, but the behavior is different from the above in some reactions. ${ }^{8} \quad$ It is obvious that the catalytic reaction with isolated complexes is advantageous more than that with in situ formed ${ }^{6}$ catalysts or catalyst precursors with regard to the simplicity of handling catalysts and the reproducibility of the results. ${ }^{9}$ Then, we investigated the platinum-catalyzed enantioselective aldol reaction by utilizing the known platinum complexes as the starting catalysts. We disclose herein the ( $\mu$-hydroxo)-platinum complex-catalyzed enantioselective aldol reaction with 1 in DMF. Some platinum complexes furnished with BINAP auxiliary are known: $[((R)-\mathrm{BINAP}) \mathrm{Pt}(\mu-\mathrm{OH})]_{2} \cdot 2 \mathrm{BF}_{4}$ was used for enantioselective Baeyer-Villiger oxidations of cyclic ketones with hydrogen peroxide ${ }^{7 b}$ and $\left[((R)-\operatorname{BINAP}) \mathrm{Pt}\left(\mathrm{H}_{2} \mathrm{O}\right)(\mathrm{OTf})\right] \cdot \mathrm{OTf}$ was provided for ligand exchange reactions. ${ }^{10}$ Thus, we first chose $\mu$-hydroxo-platinum complex $2^{11}$ and monoaqua-platinum complex $\mathbf{3}^{12}$ as the catalysts having the same counter anion for the platinum-catalyzed enantioselective aldol reaction, as depicted in Figure 1.

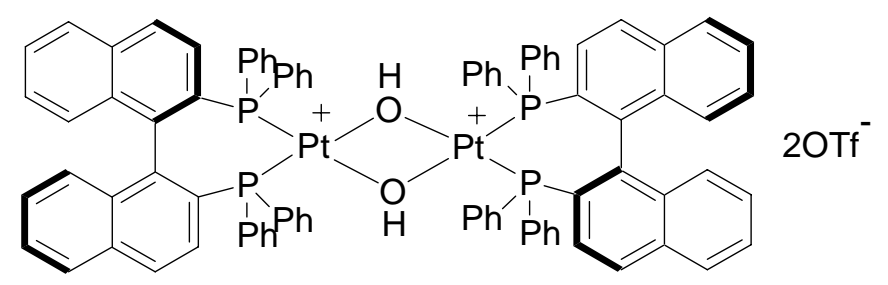

$\mu$-hydroxo complex 2

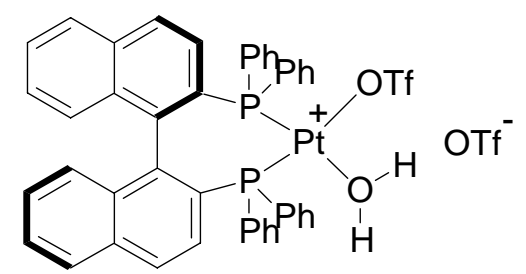

monoaqua complex 3

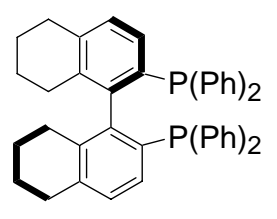

(R)- $\mathrm{H}_{8}$-BINAP

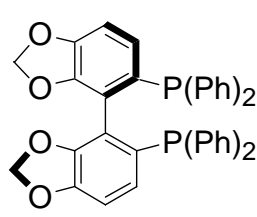

(R)-SEGPHOS

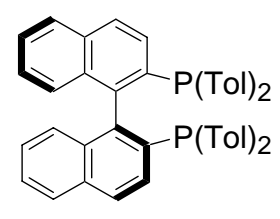

(S)-Tol-BINAP

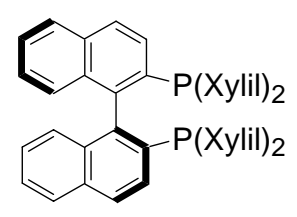

(S)-Xylyl-BINAP

Figure 1. Structures of platinum complexes and chiral auxiliary used in this study

The results are shown in Table 1 on the platinum complex-catalyzed enantioselective aldol reaction of benzaldehyde with $\mathbf{1}$ in DMF; the experimental details are described in Ref. 13 . The 
enantioselectivity in the reactions using 2 were remarkably affected by the counter anions (entries 1 , 2, 3, 5): The two anions, $\mathrm{BF}_{4}{ }^{-}$and $\mathrm{PF}_{6}{ }^{-}$, are prone to give relatively lower $\%$ ee. ${ }^{14}$ The optimized reaction (rt, $12 \mathrm{~h}, \mathrm{DMF}$ ) in the presence of $((R)$-BINAP)-2-OTf (5 mol\% on Pt) resulted in a high yield (86\%) with a high enantioselectivity (84\% ee). When ((R)-BINAP)-2-SbF 6 was used in $\mathrm{CH}_{2} \mathrm{Cl}_{2}$, the enantioselectivity was considerably reduced (entry 4). Apparently, DMF is suitable for the reaction as likely emphasized in the case of the corresponding Pd-catalyzed reaction., ${ }^{2,4}$ However, the quantity of DMF also affected both the \% yield and \% ee: Increasing from $0.3 \mathrm{~mL}$ to $1.5 \mathrm{~mL}$ of DMF seriously reduced them on the $1 \mathrm{mmol}$ scale reaction (entry 6). Moreover, lower loading of the catalyst ( $1 \mathrm{~mol} \%$ ) could not maintain the selectivity obtained in the $5 \mathrm{~mol} \%$ reaction (entry 7). With respect to the above results on DMF, the transition assembly determining the selectivity is supposed to be susceptible to the role of the solvent DMF. Structural effects of chiral modified BINAP ligands were examined in place of BINAP under the same conditions. Only $(R)$-SEGPHOS was capable of providing the aldol product of nearly the same selectivity as $(R)$-BINAP, and the other three ligands were not favored (entries 8-11). The complex, $((R)$-BINAP)-3-OTf, underwent the reaction under similar conditions to give the aldol in a moderate yield with a moderate \% ee but how the structure of the starting catalysts influences the reaction rate and selectivity is unclear (entry 12). 
Table 1. Platinum complex-catalyzed enantioselective aldol reaction of benzaldehyde with 1-methoxy-2-methyl-(1-trimethylsilyloxy)propene 1 in $\mathrm{DMF}^{\mathrm{a}}$

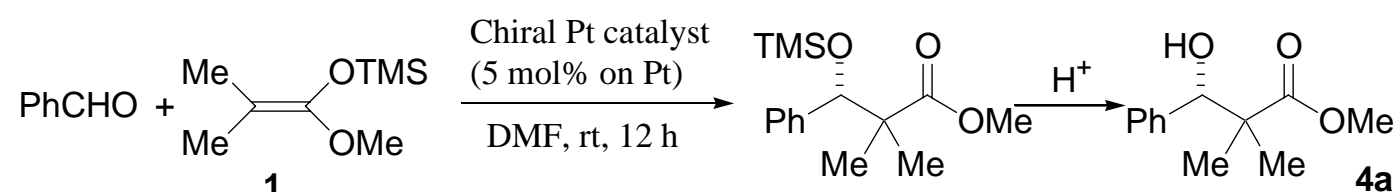

\begin{tabular}{|c|c|c|c|}
\hline Entry & Catalysts & Yield (\%) & $\% \mathrm{ee}^{\mathrm{c}}$ \\
\hline 1 & $((R)-\mathrm{BINAP})-2-\mathrm{BF}_{4}$ & 53 & 68 \\
\hline 2 & $((R)-\mathrm{BINAP})-2-\mathrm{PF}_{6}$ & 77 & 69 \\
\hline 3 & $((R)-\mathrm{BINAP})-2-\mathrm{SbF}_{6}$ & 74 & 80 \\
\hline $4^{\mathrm{d}}$ & $((R)-\mathrm{BINAP})-2-\mathrm{SbF}_{6}$ & 85 & 57 \\
\hline 5 & $((R)$-BINAP)-2-OTf & 86 & 84 \\
\hline $6^{\mathrm{e}}$ & $((R)$-BINAP)-2-OTf & 54 & 74 \\
\hline $7^{\mathrm{f}}$ & $((R)$-BINAP)-2-OTf & 27 & 36 \\
\hline 8 & ((R)-SEGPHOS)-2-OTf & 85 & 83 \\
\hline 9 & $\left((R)-\mathrm{H}_{8}\right.$-BINAP)-2-OTf & 84 & 75 \\
\hline 10 & ((R)-Tol-BINAP)-2-OTf & 81 & $79^{g}$ \\
\hline 11 & ((S)-Xylyl-BINAP)-2-OTf & 85 & $58^{g}$ \\
\hline 12 & ((R)-BINAP)-3-OTf & 72 & 68 \\
\hline
\end{tabular}

${ }^{\mathrm{a}}$ All reactions were carried out at rt with stirring under Ar: benzaldehyde (1.0 mmol), 1 (2.0 mmol), Pt complex (5 mol\%)) in DMF (0.3 mL), as described in Ref. 13 . ${ }^{\mathrm{b}}$ Isolated yields. ${ }^{\mathrm{c}}$ The $\%$ ee values were determined with HPLC (Daicel Chiralcel OD-H). ${ }^{\mathrm{d}} \mathrm{CH}_{2} \mathrm{Cl}_{2}$ was used. ${ }^{\mathrm{e}} \mathrm{DMF}(1.5 \mathrm{~mL})$ was used. ${ }^{\mathrm{f}} \mathrm{Pt}(1 \mathrm{~mol} \%)$ was used. ${ }^{\mathrm{g}}$ The opposite configuration.

Table 2 illustrates the structural effects of the substrate-aldehydes on reactivity and selectivity in the dicationic $((R)$-BINAP)-2-OTf-catalyzed enantioselective aldol reaction with $\mathbf{1}$ which was carried out with the typical procedure in DMF. Both aromatic aldehydes having electron-attracting and 
-releasing substituents gave comparable results on the yield and \% ee with benzaldehyde. A typical primary aliphatic aldehyde, hydrocinnamaldehyde, led to superior enantioselectivity. As long as $\mathbf{1}$ is used as a silyl nucleophile, ((R)-BINAP)-2-OTf plays a reliable role in the platinum-catalyzed enantioselective aldol reaction over a wide range of aldehydes, having a phenyl functional group. A linear aliphatic aldehyde, heptanal, underwent the reaction in a low yield but a high \% ee (entry 7) while secondary aldehydes did not work under the reaction conditions in analogy with Fujimura's case. 
Table 2. [((R)-BINAP)Pt( $\mu-\mathrm{OH})]_{2}$-2OTf-catalyzed

enantioselective aldol reaction of a variety of aldehydes with $\mathbf{1}^{\mathrm{a}}$
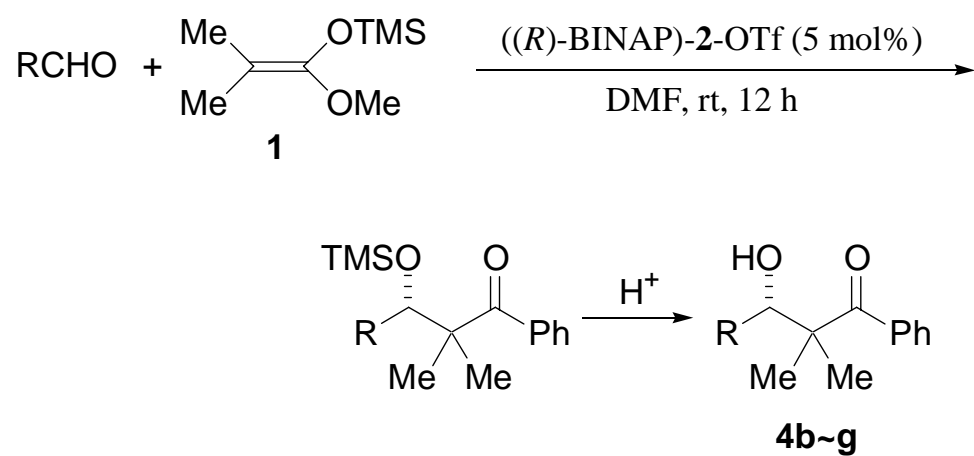

\begin{tabular}{|c|c|c|c|c|}
\hline Entry & Aldehydes & Products & Yields (\%) & $\%$ ee \\
\hline 1 & & $4 b$ & 82 & 81 \\
\hline 2 & & 4c & 89 & 82 \\
\hline 3 & & 4d & 89 & 79 \\
\hline 4 & & $4 e$ & 92 & 82 \\
\hline 5 & & $4 f$ & 77 & 72 \\
\hline 6 & & $4 g$ & 82 & 92 \\
\hline 7 & & $4 h$ & $23^{\mathrm{b}}$ & 90 \\
\hline
\end{tabular}

${ }^{\mathrm{a}}$ The reaction was carried out according to the typical procedure described in Ref. 13.

${ }^{\mathrm{b}}$ The reaction time was $24 \mathrm{~h}$.

In conclusion, our practically simplified mild procedure, starting with a known complex ((R)-BINAP)-2-OTf, turned out to be available for the platinum-catalyzed enantioselective aldol reaction of a variety of aldehydes with a silyl ketene acetal $\mathbf{1}$. Studies with other silyl ketene 
acetals for acyclic stereoselection accompanying high enantioselectivity are in progress. Mechanistic studies of whether the reaction in question proceeds in a Lewis acid catalyzed manner or through a pathway involving platinum enolates are also under investigation.

\section{Acknowledgements}

We thank the Takasago International Corporation for the generous gift of $(R)$-SEGPHOS and $(R)-\mathrm{H}_{8}$-BINAP. This work was supported by a Grant-in-Aid for Scientific Research from Japan Society for the Promotion of Science.

\section{References and notes}

1. Modern Aldol Reactions; Mahrwald, R.; Ed.; Wiley-VCH: Weinheim, 2004.

2. (a) Sodeoka, M.; Ohrai, K.; Shibasaki, M. J. Org. Chem. 1995, 60, 2648.

(b) Sodeoka, M.; Tokunoh, R.; Miyazaki, F.; Hagiwara, E.; Shibasaki, M. Synlett 1997, 463. (c) Sodeoka, M.; Hamashima, Y. Bull. Chem. Soc. Jpn. 2005, 78, 941.

3. Fujimura, O. J. Am. Chem. Soc. 1998, 120, 10032.

4. (a) Kiyooka, S. -i.; Hosokawa, S.; Tsukasa, S. Tetrahedron Lett. 2006, 47, 3959. (b) Kiyooka, S. -i.; Takeshita, Y.; Tanaka, Y.; Higaki, T.; Wada, Y. Tetrahedron Lett. 2006, 47, 4453.

5. Iterative enantioselective aldol reactions using silyl ketene acetals for constructing 1,3-polyols. An example: Kiyooka S. -i.; Shahid, K. A.; Goto, F.; Okazaki, M.; Shuto, Y. J. Org. Chem. 2003, 68, 7967.

6. Anktin, C.; Pregosin, P. S.; Bachechi, F.; Mura, P.; Zambonelli, I. J. Organomet. Chem. 1981, 222, 175.

7. (a) Gusso, A.; Baccin, C.; Pinna, F.; Struckul, G. Organometallics 1994, 13, 3442. (b) Strukul, G.; Varagnolo, A.; Pinna, F. J. Mol. Catal. A: Chem. 1997, 117, 413. (c) Paneghetti, C.; Gavagnin, R.; Pinna, F.; Strukul, G. Organometallics 1999, 18, 5057. (d) Pignat, K.; Vallotto, J.; Pinna, F.; Strukul, G. Organometallics 2000, 19, 5160.

8. Enantioselective Baeyer-Villiger oxidation : Ref. 7b and enantioselective Diels-Alder reaction : Ghosh, A. K.; Matsuda, H. Org. Lett. 1991, 1, 2157.

9. Unpublished results, Kiyooka, S. -i.; Matsumoto, S.: The dicationic species in situ formed from ((S)-BINAP) $\mathrm{PtCl}_{2}$ and $\mathrm{AgPF}_{6}$ in the presence of $3 \AA$ molecular sieves, according to the procedure used in the Pd enolate studies (Ref. 4), underwent the enantioselective aldol reaction in a good performance on yield and enantioselectivity. 
10. Stang, P. T.; Olenyuk, B.; Arif, A. M. Organometallics 1995, 14, 5281.

11. $[((R) \text {-BINAP }) \operatorname{Pt}(\mu-\mathrm{OH})]_{2} \cdot 2 \mathrm{OTf}$ was prepared according to the synthetic procedure for the corresponding $\mathrm{BF}_{4}$ congener reported by Strukul (Ref. 7b): ${ }^{31} \mathrm{P}$ NMR $\left(160 \mathrm{MHz}, \mathrm{CDCl}_{3}\right) \delta 3.64$ $\left(J_{\text {Pt-P }}=3625 \mathrm{~Hz}\right)$.

12. [((R)-BINAP)Pt( $\left.\left.\mathrm{H}_{2} \mathrm{O}\right)(\mathrm{OTf})\right] \cdot \mathrm{OTf}$ was prepared according to the procedure of Stang (Ref. 10): ${ }^{31} \mathrm{P}$ NMR $\left(160 \mathrm{MHz}, \mathrm{CDCl}_{3}\right) \delta 2.71\left(\mathrm{~J}_{\mathrm{Pt}-\mathrm{P}}=4020 \mathrm{~Hz}\right)$.

13. A typical procedure (5 mol\% catalytic reaction) is as follows: To a mixture of [((R)-BINAP)Pt $(\mu-\mathrm{OH})]_{2} \cdot 2 \mathrm{OTf}$ (49 mg, $0.025 \mathrm{mmol}: 0.05 \mathrm{mmol}$ on Pt) in dry DMF (0.3 mL) was added silyl nucleophile $1(405 \mu \mathrm{L}, 2.0 \mathrm{mmol})$ at rt under Ar. After the solution was stirred at room temperature for $10 \mathrm{~min}$, benzaldehyde $(102 \mu \mathrm{L}, 1.0 \mathrm{mmol})$ was added. The solution was stirred for $12 \mathrm{~h}$. The formation of the silylated aldol product was checked by the use of the corresponding spot ( $R f, 0.70)$ on TLC (20\% AcOEt/n-hexane). The reaction was quenched upon the addition of $10 \%$ aq $\mathrm{HCl}(5 \mathrm{~mL})$ and diethyl ether $(10 \mathrm{~mL})$. After stirring for $10 \mathrm{~min}$, the deprotected aldol was extracted with diethyl ether $(20 \mathrm{~mL} \mathrm{x2})$. The organic layer was dried over anhydrous $\mathrm{MgSO}_{4}$. The solvent was evaporated in vacuo to give a crude residue. The crude residue was purified by flash column chromatography $\left(\mathrm{SiO}_{2}\right)(10 \% \mathrm{AcOEt} / n$-hexane) to give $178 \mathrm{mg}$ in a 86\% yield. ${ }^{1} \mathrm{H}$ NMR (400 MHz, $\left.\mathrm{CDCl}_{3}\right) \delta 1.11$ (s, 3H, 1.15 (s, 3H), 2.17 (s, 3H), 3.08 (d, $J=4.16 \mathrm{~Hz}, 1 \mathrm{H}), 3.73$ (s, 3H), 4.90 (d, $J=4.16 \mathrm{~Hz}, 1 \mathrm{H}), 7.35-7.28$ (m, 5H). The optical purity of the product was determined by HPLC analysis with a DAICEL CHIRALCEL OD-H column to be $84 \%$ ee. The optical rotation was measured to be $[\alpha]_{\mathrm{D}}^{22}=+21.50^{\circ}$ (c 2.0 , $\mathrm{CH}_{2} \mathrm{Cl}_{2}$ ). Although the absolute configuration of the product 4a was not reported in Ref. 3, we decided it with the other products as follows: The absolute configurations were assigned in comparison with the authentic samples, which were prepared by our chiral oxazaborolidinone-catalyzed enantioselective aldol reactions: Kiyooka, S. -i.; Kaneko, Y.; Komura, M.; Matsuo, H.; Nakano, M. J. Org. Chem. 1991, 56, 2276. The reported data of 4a: Kobayashi, S.; Ishitani, H.; Yamashita, Y.; Ueno, M.; Shimizu, H. Tetrahedron 2001, 57, 861: Zirconium catalyzed enantioselective aldol reaction, $(S)$-isomer of $97 \%$ ee: $[\alpha]_{\mathrm{D}}^{25}=+5.70^{\circ}$ (c 2.49, MeOH). Fu, F.; Teo, Y. -C.; Loh, T. -P. Tetrahedron Lett. 2006, 47, 4267: Indium catalyzed enantioselective aldol reaction, $(S)$-isomer of $64 \%$ ee: $[\alpha]_{\mathrm{D}}=+13.43^{\circ}$ (c 8.43, $\mathrm{CH}_{2} \mathrm{Cl}_{2}$ ). The enantiomeric excesses in Table 1 and 2 were determined by HPLC analysis employing a DAICEL CHIRALCEL OD-H and DJ-H columns: $R f$ values (flow rate, $1 \mathrm{~mL} / \mathrm{min}$ ) of the products; 4a (OD-H, 0.7\% 2-propanol $/ n$-hexane) $t_{1}=60 \mathrm{~min}$ (major) and $t_{2}=66 \mathrm{~min}$ (minor): (OJ-H, 2\% 2-propanol $/ n$-hexane) $t_{1}=20 \mathrm{~min}$ (major) and $t_{2}=27 \mathrm{~min}$ (minor); 4b (OD-H, 1\% 2-propanol $/ n$-hexane) $t_{1}=29 \mathrm{~min}$ (major) and $t_{2}=47 \mathrm{~min}$ (minor); 4c (OD-H, 5\% 2-propanol $/ n$-hexane) $t_{1}=30 \mathrm{~min}$ (major) and $t_{2}=38 \mathrm{~min}$ (minor); 4d (OD-H, 5\% 2-propanol $/ n$-hexane) $t_{1}=34 \mathrm{~min}$ (major) and $t_{2}=47 \mathrm{~min}$ (minor); 4e (OD-H, 1\% 
2-propanol $/ n$-hexane) $t_{1}=101 \mathrm{~min}$ (major) and $t_{2}=134 \mathrm{~min}$ (minor); 4f (OD-H, 1\% 2-propanol $/ n$-hexane) $t_{1}=63 \mathrm{~min}$ (major) and $t_{2}=92 \mathrm{~min}$ (minor); $4 \mathbf{g}$ (OD-H, 2\% 2-propanol $/ n$-hexane) $t_{1}=19 \min$ (major) and $t_{2}=35 \mathrm{~min}$ (minor); $4 \mathbf{h}$ (OD-H, 0.5\% 2-propanol $/ n$-hexane) $t_{1}=9 \mathrm{~min}$ (major) and $t_{2}=12 \mathrm{~min}$ (minor).

14. $[((R) \text {-BINAP }) \operatorname{Pt}(\mu-\mathrm{OH})]_{2} \cdot 2 \mathrm{BF}_{4}$ has been used only once under similar reaction conditions $\left(-25^{\circ} \mathrm{C}, \mathrm{CH}_{2} \mathrm{Cl}_{2}\right)$ but the reaction failed miserably (27\% yield, $16 \%$ ee) (Ref. 3 ). 
( $\mu$-Hydroxo)-platinum complex-catalyzed enantioselective aldol reaction of aldehydes with 1-methoxy-2-methyl-1-(trimethylsilyloxy)propene in DMF

Syun-ichi Kiyooka,* Satoshi Matsumoto, Masafumi Kojima, Kazuyuki Sakonaka and Hirofumi Maeda
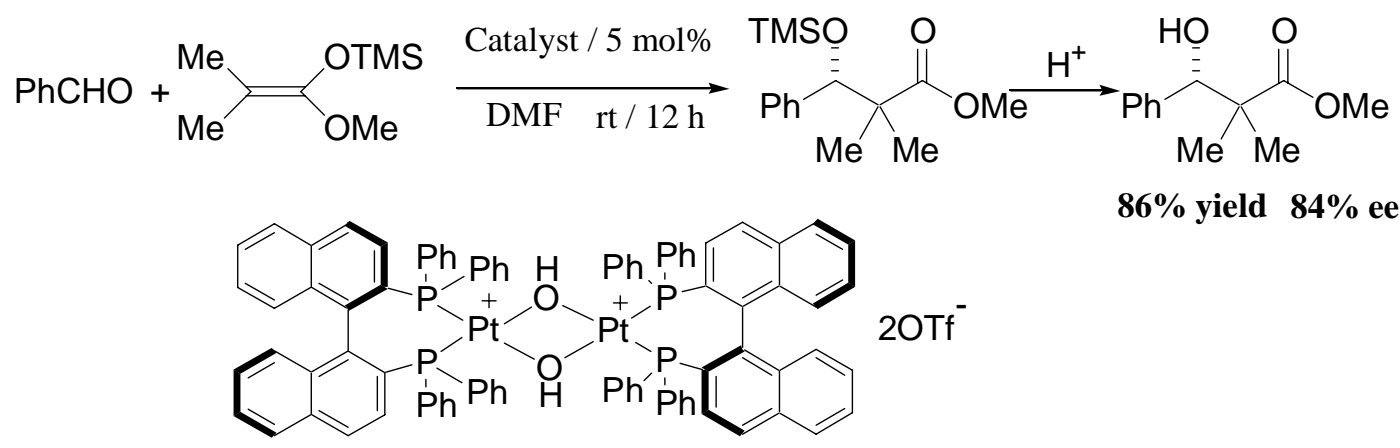

$86 \%$ yield $84 \%$ ee 